respect, this book fills the gap particularly well and is most welcome.

The first edition of 'Assisted ventilation' was based on a series of short articles published in the British Medical Fournal. This second edition has been considerably revised with the addition of other authors, all practising in the UK.

The first chapter describes in a very readable manner equipment used for artificial ventilation and this is followed by a description of the indications for mechanical ventilation. This chapter contains practical advice and describes typical settings of the equipment used for assisted ventilation. There is a comprehensive chapter on the case of the ventilated patient, with good advice on the management of tracheostomies and the reader is also reminded of the problems of psychological and sleep disturbances in critically ill patients. The chapter on weaning emphasises the importance of the respiratory muscle pump and provides an excellent account of the mechanisms of ventilatory failure. The last chapter describes techniques of non-invasive ventilation with practical advice on the initiation of nasal ventilation. However, this chapter mainly focuses on patients with chronic ventilatory failure, unlike the remainder of the book which deals with ventilation in the intensive care unit. There is relatively little mention of the use of non-invasive ventilation in acute-on-chronic respiratory failure; yet this is the situation when nasal ventilation can be particularly difficult to administer. Perhaps the third edition will expand on this point.

This book is well illustrated with clear diagrams and useful tables and there are good reference sections. I would recommend that it is read by both physicians and anaesthetists involved in the management of patients with respiratory failure. It will also be useful to physiotherapists and nurses involved in the management of these patients.

JA WEDZICHA

London Chest Hospital, London E2 $9 \mathcal{F X}, U K$

\section{Historical connections}

Medicine in the making of modern Britain 1700-1920, C Lawrence. pp 91 , Routledge, London, 1994. £6.99, paperback

The role of medicine in the political and social developments of the last three centuries is the subject of this book in the 'Historical connections' series.

Lawrence's central theme is that medicine has been a powerful weapon in the hands of both reactionaries and reformers. During the 18th century, doctors tended to use their knowledge in the interests of conservatism; their concept of body and disease stressed the importance of 'natural place' and of bodily matter not crossing its proper boundaries.

The 19th century saw the age of reform when the conservatives were challenged by radicals in the profession who believed that the natural order was not static but could and should be reformed. The authority of science superceded that of religion, medical intervention was seen as a powerful instrument for effecting social progress and medical men provided many of the categories through which people explained the world.

According to Lawrence, and implicit in the book's title, medicine has made little further impact on the social and political develop- ment of Britain since 1920 . By then, we are told, many of the ideas and practices of modern medicine were already in place. This may come as a surprise to those who have been practising as doctors during the second half of this century - and a disappointment to readers who would have welcomed the application of Lawrence's original thought and lucid style to the role of medicine in the Britain of the 1990s. The importance which the author attaches to medicine as a prime mover in social reform and progress migh well be challenged by groups with similar claims - churchmen and lawyers, for example - but Lawrence does make a convincing case and the book as a whole provides an enjoyable and challenging read.

COLIN OGILVIE

The Riffel, Woolton Park, Liverpool L25 6DR, UK

\section{Genetics}

Annual review of genetics, vol 27, A Campbell, W Anderson, EW Jones, eds. pp 557, illustrated. Annual Reviews, Palo Alto, California, USA, 1993. £23.00, hardback

This volume contains 16 articles, some of which are of medical interest. From the public health point of view, there is a review of the activation of pro-mutagens in the environment by green plants and for the virologist, a review of the genetics of the normal and attenuated phenotypes of poliovirus.

For the medical geneticist, relevant articles include genomic imprinting, sex determination in mammals and DNA repair genes. Morton briefly reviews genetic epidemiology, but the speed of the developments he describes ensures that some descriptions are already out of date, eg, diabetes, where some loci have been mapped by sib-pair analysis, a method condemned by Morton as inexact and inefficient. He gives a concise listing of the problems with such analyses.

Many articles provide an insight into basic genetics. Birchler reviews maize endosperm development and comments upon the effect of aneuploidy. Mapping polygenes in plants reveals the power of molecular genetics in estimating the number of polygenes, the magnitude of their individual effects and degree of interaction. The possibility of mapping polygenes in humans by comparative mapping is briefly mentioned.

Detailed reviews of meiotic segregation and the molecular genetics of the kinesin superfamily of genes (involved in intra-cellular transport) are given. Inter-cellular signalling in the nematode $C$ elegans is reviewed. Nearly all classes of signal transducers in mammals are present in this organism.

There are articles in this volume to interest clinicians and much to interest researchers. It should find a place on the bookshelves in academic departments of genetics.

ALAN FRYER Consultant Clinical Geneticis Royal Liverpool University Hospital PO Box 147, Liverpool L69 3BX, UK

\section{Postgraduate training in the US}

\section{Getting into a residency - guide for} medical students, 3rd edn, KV Iserson. pp 433, illustrated. Galen, Arizona, USA, 1993. $£ 15.00$, paperback
This manual provides in minute detail a modus vivandi for the American medical student embarking on a postgraduate training. I is not surprising that this should have become a standard reference work, by a dedicated teacher and clinician with the able assistance of his wife who has provided computing skills and a smattering of business science. It is indeed remarkable for the detailed advice given with almost maternal concern. There is even a section advising the young medical student on how to pack a suitcase before travelling to his interview. In general there is very little relevant material for the UK medical student whose specialist training is still generally achieved by accident. Nevertheless it provides an interesting insight into the American system which sadly seems to contrast with our own in requiring a greate degree of motivation, competitiveness, and longer hours of duty than will be required with the New Deal. The emphasis still seems to be on maximal quality of training, if necessary at the expense of conditions of service which we would now regard officially as unacceptable. However, some of the terms relating to undergraduate training in the US (eg mentors, OSCE) are beginning to feature in the new curriculum and the Continuum training post is obviously conceptually close to a Residency. Some of the terminology is interesting though unfamiliar. 'Physiatry' doesn't feature in any UK list of specialities and official training in osteopathy (?homeopathy) has yet to be considered in parallel with its allopathic counterpart Whilst much of the advice is given as fireside chat Dr Iserson has a tendency to revert to businessease with trendy but irrelevan algorithms. Pithy quotations at the start of every chapter may not necessarily appeal. There are interesting sections on constructing a resume $(\mathrm{CV})$ in anticipation of questions at the interview, from which both the victims and interviewers could certainly benefit.

I doubt that this book will be of interest other than to medical educators and to the diminishing number of UK students seeking postgraduate training in the USA. As such i should be provided by medical school libraries as a useful source of reference.

MC BISHOP

Clinical Sub-Dean

University of Nottingham, Queen's Medical Centre, Nottingham NG7 2UH, UK

\section{Neuroendocrine tumours}

Diagnostic histopathology of neuroendocrine tumours, JM Polak, ed. pp 290, illustrated. Churchill Livingstone, London, 1993. $£ 95.00$, hardback

Neuroendocrine tumours are of abiding interest for many reasons and a book like this is most welcome. In 11 chapters, various authors cover not only the pathology of neuroendocrine tumours of the gastroenteropancreatic system, the respiratory tract, the thyroid and parathyroids, pituitary, paraganglia and skin, but also review methods for their detection and investigation, their genetics, the pathophysiology of the peptides they secrete and the transgenic models used in their study. All of these contain useful in formation, although it must be said that, for the histopathologist faced with a diagnostic problem in this area but without the appro- 